\title{
What effect do attempts to lose weight have on the observed relationship between nutrition behaviors and body mass index among adolescents?

\author{
Jennifer Utter*1, Robert Scragg1, Cliona Ni Mhurchu ${ }^{2}$ and David Schaaf ${ }^{3}$
}

Address: ${ }^{1}$ Epidemiology and Biostatistics, School of Population Health, University of Auckland, Auckland, New Zealand, ${ }^{2}$ Clinical Trials Research Unit, School of Population Health, University of Auckland, Auckland, New Zealand and ${ }^{3}$ Pacific Health, School of Population Health, University of Auckland, Auckland, New Zealand

Email: Jennifer Utter* - j.utter@auckland.ac.nz; Robert Scragg - r.scragg@auckland.ac.nz; Cliona Ni

Mhurchu - c.nimhurchu@ctru.auckland.ac.nz; David Schaaf -d.schaaf@auckland.ac.nz

* Corresponding author

Published: 19 September 2007

International Journal of Behavioral Nutrition and Physical Activity 2007, 4:40 $5868-4-40$

This article is available from: http://www.ijbnpa.org/content/4/I/40

This is an Open Access article distributed under the terms of the Creative Commons Attribution License (http://creativecommons.org/licenses/by/2.0), which permits unrestricted use, distribution, and reproduction in any medium, provided the original work is properly cited.

\begin{abstract}
Background: Little research has given consideration to how people's weight control behaviors may moderate the relationships between nutrition and body mass index (BMI) in large cross-sectional studies. The objective of the current study is to determine how attempts to lose weight confound the relationships between nutrition behaviors and BMI among a population of predominately overweight adolescents.

Methods: Data were drawn from the baseline measurements of the Pacific OPIC (Obesity Prevention In Communities). Participants included approximately 3500 high school students in New Zealand. Students in the sample primarily identified as a Pacific Island ethnicity (57\%) and the mean age for participants was I 4.8 years. Participants completed a questionnaire about nutrition and physical activity patterns and were weighed and measured for height.

Results: In our sample, $57 \%$ of students were overweight/obese, with the highest prevalence among Pacific Island students (7I\%). Approximately $50 \%$ of students were currently trying to lose weight, and this was more common among females, Pacific Island students and overweight/obese students. Examination of the nutritional correlates of BMI in the total population found inverse relationships between $\mathrm{BMI}$ and consumption of high-fat/high-sugar foods and positive relationships between BMI and eating 5 or more fruits and vegetables a day (all significant after controlling for age, sex, and ethnicity). For example, students who drank the most soft drinks or ate fruit and vegetables infrequently had the lowest mean BMI. Students' attempts to change their weight significantly moderated the relationships between most nutritional behaviors and BMI. In most cases, among students not trying to change their weight, expected relationships were observed; among students trying to lose weight, unexpected or no relationships were observed.

Conclusion: Our findings suggest that among this population of predominately overweight students, solely relying on cross-sectional findings between nutrition behaviours and BMI would misinform intervention strategies. It appears that many students are already taking appropriate steps to reduce their weight. Intervention efforts should now move beyond education-based strategies to environmental changes that support students in adopting healthier nutrition practices.
\end{abstract}




\section{Background}

In New Zealand, approximately one third of children aged 5-14 years are overweight or obese[1] and, when compared internationally, it has been estimated that New Zealand has witnessed an annual increase in the prevalence of childhood obesity greater than most other industrialised countries[2]. With the increasing awareness of the health implications of obesity, weight control behaviors are now common among adolescents in New Zealand. More than $60 \%$ of girls and $29 \%$ of boys are trying to lose weight[3]. International research has documented that weight control behaviors are more common among overweight adolescents [4] and that the most common types of weight control strategies adolescents employ are dietary changes and increasing their physical activity[5].

Little research has given consideration to how people's weight control behaviors may moderate the relationships between nutrition behaviors and body mass index (BMI) in large cross-sectional studies. This is important because nutrition and health surveys often identify the associations between dietary and activity patterns and obesity and these findings form the basis of many intervention strategies and weight loss advice. For example, the positive cross-sectional associations between television viewing and obesity were being reported as early as 1985[6]. Consequently, reducing television viewing became a significant component of several obesity prevention interventions[7,8]. Given the increasing prevalence of obesity and the general awareness of related issues, it is possible that cross-sectional research may be increasingly confounded by the weight control attempts of its population. While it is most likely that unexpected findings go unreported, one study from the Third National Health and Nutrition Examination Survey highlighted that low water consumption and high energy consumption were significantly associated with a healthful weight among adolescents [9]. One possible explanation for this finding may be that overweight students are drinking more water and reducing their caloric intake as a way to control their weight. Without adequate discussion of these unpredicted findings, there may be potentially serious implications for obesity prevention efforts: increased water consumption and reduced caloric intake become reported as significant correlates of overweight and obesity.

Thus, the aim of the current study is to determine the nutritional correlates of obesity (e.g. consumption of breakfast, fruits and vegetables, and high-fat/high-sugar foods) among a predominately overweight population of high school students in New Zealand and to determine how students' attempts to change their weight moderates the cross-sectional relationships between BMI and nutritional behaviors.

\section{Methods \\ Study design}

Data for the current study were collected during baseline measurements of the Pacific OPIC (Obesity Prevention in Communities) Project. OPIC is a four country community-based obesity prevention study among predominately Pacific adolescents with sites in Australia, New Zealand, Fiji and Tonga. Data for the current study were drawn from participants at the New Zealand site. Students from seven high schools in South Auckland were invited to participate. These schools were purposively selected for inclusion in the study because they had sufficient numbers of Pacific Island students and were in close proximity to each other. All of the schools participating in the study were classified as decile 1 or 2; school deciles reflect the socioeconomic position of its students and range from 1 (most deprived) to 10 (least deprived).

Students completed a questionnaire about their eating and physical activity patterns on a hand-held computer and were weighed and measured for height. All data were collected at school, during the school day, and in the presence of trained staff between February and October 2005. The University of Auckland Human Participants Ethics Committee granted ethical approval for the study. Active consent was received by students aged 16 years and older and by parents/guardians of students under the age of 16 .

\section{Participants}

All students attending school during the days of data collection were invited to participate. Based on the school rolls, it was estimated that 6766 students were eligible for participation. The final study response rate was $54 \%$ ( $n=$ 3626); information about the non-responders was not available. The study sample was comprised of slightly more females (52\%) than males $(48 \%)$ and had a mean age of 14.8 years (range 12 to 20 years). Students in the final study sample identified their ethnicity primarily as Pacific Island (57\%), followed by New Zealand Maori (20\%), then European (12\%) and Asian/other (11\%).

\section{Measures}

Sociodemographic characteristics

Students' ethnicity, age and gender were each assessed by self-report. Students were asked which ethnic group they most identified with and were given 11 ethnicities from which to choose. Students were then categorised into four main ethnic groups: 'Pacific' (Samoan, Cook Island Maori, Tongan, Niuean, or Other Pacific), 'Maori', 'European' (NZ European or Other European), and 'Asian/ other' (Chinese, Indian, Other).

\section{Weight change attempts}

Weight change attempts were assessed by one question asking students what they were currently trying to do about 
their weight. Students could respond, 'lose weight', 'gain weight', 'stay the same weight', or 'I'm not trying to do anything about my weight.' The last two categories were combined for analyses and are referred to as 'not change weight'.

\section{BMI}

Height and weight measurements were taken by trained research staff using standardised protocols. Students wore light clothing and no shoes. Students' weights were measured to the nearest $0.1 \mathrm{~kg}$ using a digital scale. Students' heights were measured to the nearest $0.1 \mathrm{~cm}$ using a freestanding portable stadiometer. Body mass index (BMI) was calculated as weight (kilograms) divided by height (meters) squared. Weight status (obese, overweight, and normal weight) was defined using international definitions for children and adolescents[10].

\section{Nutrition behaviors}

The nutrition behaviors chosen for analyses were selected because of the available evidence in New Zealand and internationally, which indicates these behaviors as correlates of overweight and obesity[6,11-15]. Breakfast consumption was assessed with the question, 'In the last 5 school days, on how many days did you have something to eat for breakfast before school started?' Students were asked about their usual fruit and vegetable consumption separately with the questions, 'How many serves of fruit (vegetables) do you usually eat each day?' Fast food/takeaway food consumption was assessed with the question, 'How often do you usually eat food from a takeaway?' (local examples provided). Consumption of after school snacks that were high in fat or high in sugar was assessed with two questions about the frequency of eating fried foods or chocolates, sweets, or ice cream after school. Soft drink consumption was estimated with two questions: 'In the last 5 school days (including time spent at home), on how many days did you have regular (non-diet) soft drinks?' and 'On the last school day, how many glasses or cans of soft drinks did you have? Average soft drink consumption was estimated by multiplying the number of days soft drinks were consumed by the previous day's consumption and then averaged over the previous five school days. The estimated amounts were then categorised into five categories of approximate quintiles.

\section{Analysis}

The survey procedures in the statistical software SAS (Cary, NC, version 9.1) were used to correct design effects from clustered sampling. The demographic characteristics describing students by their weight status and weight control attempts were generated by cross-tabulations using chi-square tests to determine statistical differences. The analyses describing the demographic characteristics of students by their weight control attempts were conducted stratified by gender because males and females differ in their desires to change their weight[3] Multivariate regression models were used to determine the associations between each nutrition behavior and BMI, while controlling for age, sex, and ethnicity. A separate set of multivariate regression models were used to examine the effect of the interaction between each of the nutrition behaviors and weight change attempts on BMI while controlling for age, sex, and ethnicity. A test was considered to be statistically significant if $\mathrm{p}<0.05$.

\section{Results}

Nearly $60 \%$ of the participating students in the sample were overweight/obese (Table 1). Weight status was not associated with age or gender, but was significantly associated with ethnicity. Pacific Island adolescents were more likely to be overweight/obese $(71 \%)$, and Asian/other adolescents less likely to be overweight/obese (28\%), compared with adolescents of other ethnicities. Nearly half of all students were trying to lose weight, $40 \%$ were trying to stay the same weight or were doing nothing about their weight, and $14 \%$ were trying to gain weight (Table 2). A higher proportion of females than males were trying to lose weight, similar proportions of males and females were not trying to change their weight, and more males than females were trying to gain weight. Age was associated with attempting to change weight in males but not females. Among males, younger adolescents were more likely to report attempting to lose weight, while older adolescents were more likely to be trying to gain weight. For both genders, ethnicity and weight status were significantly associated with weight change attempts. Pacific Island students and overweight/obese students were more likely to be trying to lose weight.

The relationships between each of the nutrition behaviors and BMI for the total sample are displayed in Table 3. Significant inverse relationships between BMI and consumption of breakfast, fast food/takeaways, and high fat or high sugar after school snacks were observed. For example, students who ate breakfast on all of the past five school days, and who ate fast food takeaways most days of the week, had significantly lower mean BMIs than students who never ate breakfast or who ate fast food takeaway less than once per month. Conversely, students who reported eating five or more fruits and vegetables a day had a significantly higher mean BMI $(p=0.002)$ than students who did not.

Table 4 describes how weight change attempts moderate the relationships between each of the nutrition behaviors and BMI. The p-values reflect the significance of the interaction terms (expressed as nutrition behaviour*weight change attempt) controlling for age, sex, and ethnicity. The mean BMI for each behavior, stratified by weight 
Table I: Demographic characteristics of study population by weight status.

\begin{tabular}{|c|c|c|c|c|c|c|c|c|c|c|}
\hline & \multicolumn{3}{|c|}{ Obese } & \multirow[b]{2}{*}{$\mathrm{n}$} & \multicolumn{3}{|c|}{ Overweight } & \multicolumn{2}{|c|}{ Normal weight } & \multirow[b]{2}{*}{ p-value 3} \\
\hline & $\mathrm{n}$ & $\% 1$ & $\mathrm{SE}^{2}$ & & $\%$ & SE & $\mathrm{n}$ & $\%$ & SE & \\
\hline Total & 926 & 26.5 & 2.9 & 1100 & 31.5 & 1.7 & 1464 & 41.9 & 3.8 & \\
\hline \multicolumn{11}{|l|}{ Gender } \\
\hline Male & 436 & 26.2 & 2.6 & 508 & 30.5 & 1.5 & 719 & 43.2 & 3.3 & \\
\hline Female & 490 & 26.8 & 3.3 & 592 & 32.4 & 2.2 & 745 & 40.8 & 4.5 & 0.31 \\
\hline \multicolumn{11}{|l|}{ Age } \\
\hline $\begin{array}{l}12-13 \\
\text { years }\end{array}$ & 230 & 29.8 & 1.5 & 251 & 32.5 & 2.5 & 292 & 37.8 & 3.0 & \\
\hline 14 years & 225 & 26.3 & 3.2 & 277 & 32.3 & 3.5 & 355 & 41.4 & 3.4 & \\
\hline 15 years & 164 & 23.5 & 3.8 & 219 & 31.4 & 2.9 & 314 & 45.1 & 6.1 & \\
\hline 16 years & 159 & 25.8 & 3.3 & 194 & 31.4 & 2.2 & 264 & 42.8 & 4.6 & \\
\hline $17+$ years & 148 & 27.1 & 5.3 & 159 & 29.1 & 1.5 & 239 & 43.8 & 5.5 & 0.54 \\
\hline \multicolumn{11}{|l|}{ Ethnicity } \\
\hline $\begin{array}{l}\text { Pacific } \\
\text { Island }\end{array}$ & 690 & 34.6 & 1.4 & 721 & 36.1 & 1.2 & 584 & 29.3 & 0.7 & \\
\hline Maori & 164 & 23.1 & 2.9 & 212 & 23.1 & 2.9 & 334 & 47.0 & 2.3 & \\
\hline $\begin{array}{l}\text { Asian/ } \\
\text { other }\end{array}$ & 26 & 6.9 & 2.0 & 79 & 20.9 & 1.5 & 273 & 72.2 & 1.5 & \\
\hline European & 46 & 11.3 & 4.8 & 88 & 21.6 & 3.3 & 273 & 67.1 & 5.5 & $<0.001$ \\
\hline
\end{tabular}

I Row percentage, unadjusted for confounders

2Standard error (SE) for percentage

${ }^{3} \mathrm{P}$-value for chi-square

change attempt, describes the direction of the interaction. In most analyses, weight change attempts significantly moderated the effect of the nutrition behaviors and BMI. The most significant interactions are visually displayed in Figures 1, 2, 3, 4. Among students not trying to change their weight, eating five fruits and vegetables a day (Figure 1) or having fruit as an after school snack (Figure 2) is associated with a lower BMI, while among students trying to lose weight the reverse is true. More frequent consumption of fast food/takeaways (Figure 3) and high sugar snacks after school (Figure 4) is associated with a higher BMI among students not trying to change their weight, but this relationship was not observed for students trying to lose weight. The direction of the relationships between BMI and the nutrition behaviours among the students trying to gain weight were inconsistent.

\section{Discussion}

The aim of the current study is to determine how attempts to change weight moderate the cross-sectional relationships between BMI and nutritional correlates among a predominately overweight population of high school students in New Zealand. In a population with a high percentage of students who are overweight/obese and are trying to lose weight, weight control attempts significantly moderated the relationships between nutrition behaviors and BMI. These findings have significant implications for the interpretation of future cross-sectional studies exam- ining nutritional correlates of BMI and for obesity prevention programs.

The current study population represents a group of adolescents at increased risk for obesity and related health issues. The population was predominately comprised of adolescents of Pacific Island ethnicities and from poorer socioeconomic position and, in New Zealand, childhood

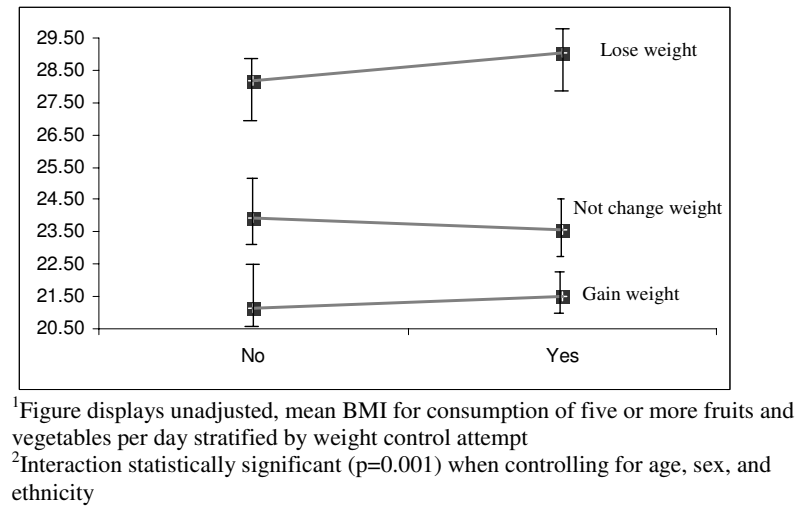

Figure I

Visual representation' of the significant interaction ${ }^{2}$ between consumption of five or more fruits and vegetables a day and weight control attempt on BMI. 


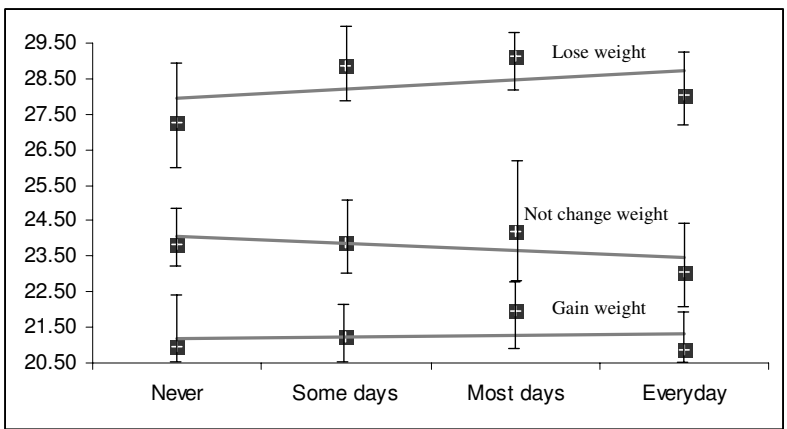

${ }^{1}$ Figure displays unadjusted, mean BMI for consumption of fruit as an afternoon snack stratified by weight control attempt

${ }^{2}$ Interaction statistically significant $(\mathrm{p}<0.001)$ when controlling for age, sex, and ethnicity

\section{Figure 2}

Visual representation' ${ }^{\prime}$ of the significant interaction ${ }^{2}$ between consumption of fruit as an afternoon snack and weight control attempt on BMI.

obesity rates are highest among these groups [1]. The prevalence of overweight/obesity among Pacific Island children in New Zealand is substantially higher than many other ethnic populations of other western countries [1618]. In our population of high school students in South Auckland, 59\% of students were overweight/obese, with more than $70 \%$ of the Pacific students classified as overweight/obese. Furthermore, nearly half of the sample was currently trying to lose weight, indicating an increased need for health advice and support for healthy eating and physical activity for this population.

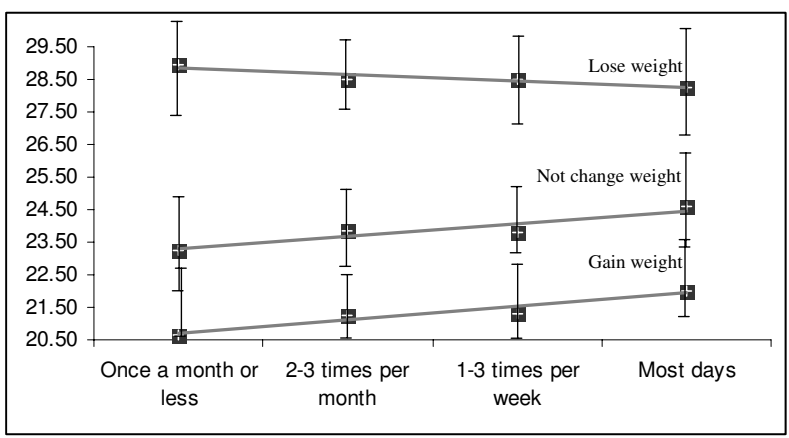

${ }^{1}$ Figure displays unadjusted, mean BMI for consumption of fast foods/ takeaway foods stratified by weight control attempt

${ }^{2}$ Interaction statistically significant $(\mathrm{p}<0.001)$ when controlling for age, sex, and ethnicity

Figure 3

Visual representation' of the significant interaction ${ }^{2}$ between consumption of fast food/takeaway foods and weight control attempt on BMI.

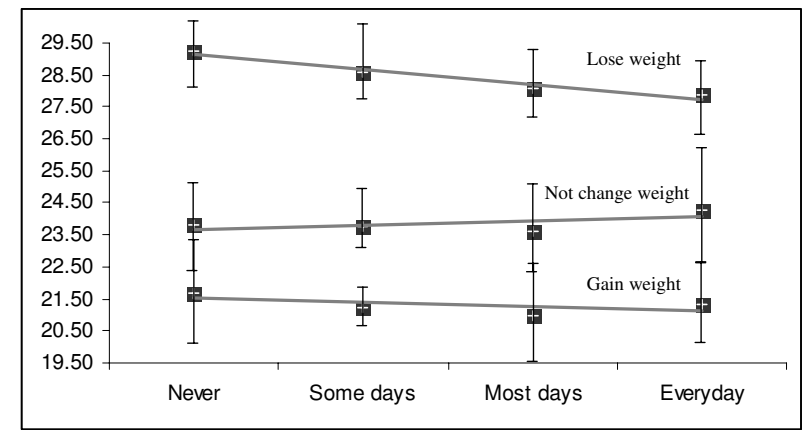

${ }^{1}$ Figure displays unadjusted, mean BMI for consumption of high sugar snack foods after school stratified by weight control attempt

${ }^{2}$ Interaction statistically significant $(\mathrm{p}<0.001)$ when controlling for age, sex, and ethnicity

\section{Figure 4}

Visual representation' of the significant interaction ${ }^{2}$ between consumption of high sugar snack foods after school and weight control attempt on BMI.

In analyses of the total sample, previously documented nutritional correlates of obesity were either not significantly associated with BMI or were significant, but in the opposite direction to that expected. These findings are inconsistent with a large body of evidence that support a positive relationship between excess body weight and skipping breakfast[13], soft drink consumption [12,1921], and eating food prepared away from home $[11,14,22]$, indicating that these behaviors should be targeted by prevention programs. We did find, however, that students' attempts to change their weight significantly moderated the relationships between BMI and consumption of breakfast, fruits and vegetables, soft drinks, fast food and high sugar/high fat afternoon snacks. In most cases, among students who were trying to lose weight, the students with the highest BMI's were eating the fewest unhealthy foods and the most healthy foods. These findings suggest that adolescents who are trying to lose weight may already be adopting the dietary changes targeted by health promotion programs, such as increasing consumption of fruits and vegetables and decreasing consumption of high-fat or high-sugar foods.

It is also possible that significant interactions observed in the current study may reflect a reporting bias whereby overweight adolescents underreported their consumption of high-fat or high-sugar snacks. Research with adults has indicated that underreporting is more common among women and those who are overweight or trying to lose weight [23]. Underreporting energy intake is also common among children and adolescents; $20 \%$ of young people 
Table 2: Demographic characteristics of study population by attempts to control their weight.

\begin{tabular}{|c|c|c|c|c|c|c|c|c|c|c|}
\hline & \multicolumn{3}{|c|}{ Lose weight } & \multicolumn{3}{|c|}{ Gain weight } & \multicolumn{3}{|c|}{ Not change weight ${ }^{\mid}$} & \multirow[b]{2}{*}{$\mathrm{P}$-value ${ }^{4}$} \\
\hline & $\mathrm{n}$ & $\%^{2}$ & $\mathrm{SE}^{3}$ & $\mathrm{n}$ & $\%$ & SE & $\mathrm{n}$ & $\%$ & SE & \\
\hline Total & 1662 & 47.6 & 1.4 & 475 & 13.6 & 0.9 & 1353 & 38.8 & 1.6 & \\
\hline \multicolumn{11}{|c|}{ MALES } \\
\hline Total & 657 & 39.5 & 1.8 & 355 & 21.4 & 1.4 & 651 & 39.2 & 2.4 & \\
\hline \multicolumn{11}{|l|}{ Age } \\
\hline $12-13$ years & 188 & 50.7 & 2.6 & 58 & 15.6 & 2.3 & 125 & 33.7 & 2.2 & \\
\hline 14 years & 177 & 42.8 & 2.0 & 80 & 19.3 & 2.7 & 157 & 37.9 & 3.5 & \\
\hline 15 years & 110 & 32.5 & 3.0 & 73 & 21.5 & 4.2 & 156 & 46.0 & 3.5 & \\
\hline 16 years & 97 & 32.7 & 1.8 & 79 & 26.6 & 3.8 & 121 & 40.7 & 3.7 & \\
\hline $17+$ years & 85 & 35.1 & 3.1 & 65 & 26.9 & 0.6 & 92 & 38.0 & 3.1 & $<0.001$ \\
\hline \multicolumn{11}{|l|}{ Ethnicity } \\
\hline Pacific Island & 452 & 46.5 & 1.3 & 204 & 21.0 & I.I & 317 & 32.6 & I.I & \\
\hline Maori & 102 & 32.9 & 4.1 & 53 & 17.1 & I.I & 155 & 50.0 & 3.6 & \\
\hline Asian/other & 50 & 25.4 & 2.4 & 69 & 35.0 & 3.4 & 78 & 39.6 & 5.4 & \\
\hline European & 53 & 29.0 & 2.7 & 29 & 15.9 & 1.8 & 101 & 55.2 & 3.1 & $<0.001$ \\
\hline \multicolumn{11}{|l|}{ Weight Status } \\
\hline Obese & 339 & 77.8 & 1.4 & 5 & 1.2 & 0.4 & 92 & 21.1 & 1.6 & \\
\hline Overweight & 221 & 43.5 & 2.4 & 73 & 14.4 & 1.9 & 214 & 42.1 & 2.5 & \\
\hline Normal weight & 97 & 13.5 & 1.5 & 277 & 38.5 & 3.4 & 345 & 48.0 & 3.3 & $<0.001$ \\
\hline \multicolumn{11}{|c|}{ FEMALES } \\
\hline Total & 1005 & 55.0 & 1.7 & 120 & 6.6 & 0.5 & 702 & 38.4 & 1.5 & \\
\hline \multicolumn{11}{|l|}{ Age } \\
\hline $12-13$ years & 210 & 52.2 & 3.0 & 26 & 6.5 & 0.8 & 166 & 41.3 & 2.8 & \\
\hline 14 years & 249 & 56.2 & 1.6 & 35 & 7.9 & 1.3 & 159 & 35.9 & 1.2 & \\
\hline 15 years & 208 & 58.1 & 2.2 & 23 & 6.4 & 0.8 & 127 & 35.5 & 2.2 & \\
\hline 16 years & 174 & 54.4 & 3.2 & 15 & 4.7 & 0.5 & $13 \mid$ & 41.0 & 3.4 & \\
\hline $17+$ years & 164 & 54.0 & 4.2 & 21 & 6.9 & 1.2 & 119 & 39.1 & 4.4 & 0.31 \\
\hline \multicolumn{11}{|l|}{ Ethnicity } \\
\hline Pacific Island & 613 & 60.0 & 1.2 & 63 & 6.2 & 0.8 & 346 & 33.9 & I.I & \\
\hline Maori & 209 & 52.3 & 2.0 & 24 & 6.0 & 0.7 & 167 & 41.8 & 1.7 & \\
\hline Asian/other & 80 & 44.2 & 3.2 & 18 & 10.0 & 2.5 & 83 & 45.9 & 2.1 & \\
\hline European & 103 & 46.0 & 4.8 & 15 & 6.7 & 1.3 & 106 & 47.3 & 4.5 & $<0.001$ \\
\hline \multicolumn{11}{|l|}{ Weight Status } \\
\hline Obese & 386 & 78.8 & 1.9 & 6 & 1.2 & 0.6 & 98 & 20.0 & 1.5 & \\
\hline Overweight & 392 & 66.2 & 1.3 & 19 & 3.2 & 0.6 & 181 & 30.6 & I.I & \\
\hline Normal weight & 227 & 30.5 & 3.3 & 95 & 12.8 & 1.6 & 423 & 56.8 & 2.3 & $<0.001$ \\
\hline
\end{tabular}

underreported their energy intake in the UK National Diet and Nutrition Survey [24]. Among adolescents, underreporting is more common among those who are older $[24,25]$ and overweight $[24,26]$. Furthermore, there has been some suggestion that measures of dietary restraint do not correspond with actual dietary restriction[27], suggesting that students who report trying to lose weight may be reporting a perceived need to lose weight rather than an actual behavior change. That said, we do not believe it to be likely that underreporting or misreporting of weight control attempts explain all of the significant interactions in our study. The strength and consistency of the interactions across several nutrition behaviors, including the healthier behaviors, and the relevance of these behaviors to health promotion messages suggests that adolescents are trying to make appropriate dietary changes. Our findings are consistent with previous research documenting that dietary changes are among the most common weight 
Table 3: Bivariate and multivariate relationships between BMI and nutrition behaviors in the total sample.

\begin{tabular}{|c|c|c|c|c|c|c|}
\hline & \multicolumn{3}{|c|}{ Bivariate Relationship } & \multicolumn{3}{|c|}{ Multivariate Relationship! } \\
\hline & $\mathrm{n}$ & Mean BMI2 & $95 \% \mathrm{Cl}^{3}$ & $\beta^{4}$ & $\mathrm{SE}^{5}$ & p-value \\
\hline \multicolumn{7}{|c|}{ Breakfast consumption (days per school week) } \\
\hline None & 689 & 26.4 & $(25.1,27.7)$ & 0.97 & 0.1 & \\
\hline $1-2$ days & 429 & 26.9 & $(25.7,28.2)$ & 0.96 & 0.4 & \\
\hline $3-4$ days & 924 & 25.9 & $(24.6,27.3)$ & 0.22 & 0.2 & \\
\hline 5 days & 1037 & 24.8 & $(23.5,26.0)$ & 0.00 & 0.0 & $<0.001$ \\
\hline \multicolumn{7}{|c|}{ Eat five or more fruits and vegetables a day } \\
\hline No & 2028 & 25.4 & $(24.1,26.7)$ & -0.78 & 0.1 & \\
\hline Yes & 1458 & 26.2 & $(25.0,27.4)$ & 0.00 & 0.0 & 0.001 \\
\hline \multicolumn{7}{|c|}{ Average daily soft drink consumption } \\
\hline Not regular drinker & 757 & 25.3 & $(23.9,26.7)$ & 0.00 & 0.0 & \\
\hline $\mathrm{I} / 2$ a can a day or less & 1053 & 25.6 & $(24.3,27.0)$ & -0.19 & 0.1 & \\
\hline I can a day & 655 & 25.8 & $(24.5,27.1)$ & -0.37 & 0.2 & \\
\hline 2 cans a day & 340 & 26.4 & $(24.8,27.9)$ & 0.23 & 0.3 & \\
\hline More than 2 cans a day & 398 & 26.0 & $(25.2,26.8)$ & -0.48 & 0.1 & 0.022 \\
\hline \multicolumn{7}{|c|}{ Fast food/takeaway consumption } \\
\hline Once a month or less & 694 & 26.2 & $(24.4,27.9)$ & 0.00 & 0.0 & \\
\hline $2-3$ times a month & 973 & 25.9 & $(24.7,27.1)$ & -0.52 & 0.3 & \\
\hline I-3 times a week & 1562 & 25.5 & $(24.4,26.6)$ & -1.25 & 0.3 & \\
\hline Most days & 256 & 25.5 & $(24.2,26.8)$ & -1.87 & 0.3 & 0.002 \\
\hline \multicolumn{7}{|c|}{ High fat foods as after school snack } \\
\hline Never & 874 & 25.4 & $(23.8,26.9)$ & 0.00 & 0.0 & \\
\hline Some days & 1735 & 26.0 & $(24.8,27.2)$ & -0.38 & 0.2 & \\
\hline Most days & 633 & 25.6 & $(24.5,26.7)$ & -1.34 & 0.2 & \\
\hline Everyday & 243 & 25.4 & $(24.2,26.6)$ & -1.66 & 0.4 & $<0.001$ \\
\hline \multicolumn{7}{|c|}{ High sugar foods as after school snack } \\
\hline Never & 744 & 26.3 & $(25.0,27.6)$ & 0.00 & 0.0 & \\
\hline Some days & 1689 & 25.8 & $(24.7,27.0)$ & -0.98 & 0.1 & \\
\hline Most days & 704 & 25.1 & $(23.9,26.4)$ & -1.90 & 0.2 & \\
\hline Everyday & 348 & 25.2 & $(23.7,26.8)$ & -1.80 & 0.2 & $<0.001$ \\
\hline \multicolumn{7}{|l|}{ Fruit as after school snack } \\
\hline Never & 480 & 24.6 & $(23.4,25.9)$ & 0.00 & 0.0 & \\
\hline Some days & 1508 & 25.9 & $(24.6,27.1)$ & 0.85 & 0.3 & \\
\hline Most days & 819 & 26.5 & $(25.2,27.8)$ & 1.79 & 0.4 & \\
\hline Everyday & 678 & 25.3 & $(23.9,26.7)$ & 0.98 & 0.4 & 0.002 \\
\hline
\end{tabular}

I Controlling for age, sex, and ethnicity

2 Unadjusted mean

$395 \%$ Confidence Interval $(\mathrm{Cl})$ for the mean

${ }^{4}$ Regression coefficient ${ }^{5}$ Standard error (SE)

control strategies employed by adolescents[5] and that adolescents who are trying to lose weight eat more fruits and vegetables than their peers $[28,29]$. By either explanation, these findings suggest that further education-based interventions in this population may not be of any additional benefit as these young people appear to know about appropriate dietary strategies for weight control.

The current study is unique in its large, ethnically diverse sample of adolescents at increased risk for obesity, but there are several limitations of our findings that are important to consider. First, because of the uniqueness of the demographic characteristics of our population, generalization of our findings to other countries or other populations with high risk for obesity are limited. Second, the final student response rate was modest at $54 \%$. Because information about the non-responders is not available, we cannot hypothesise how the non-responders may have biased our results. Third, there may be moderators other than attempts to change weight that explain the inconsistent findings between the nutrition behaviours and BMI in the current study. For example, the only indicator of soci- 
Table 4: Relationships between BMI and nutrition behaviors stratified by weight control attempt.

\begin{tabular}{|c|c|c|c|c|c|c|c|c|c|c|}
\hline & \multicolumn{3}{|c|}{ Lose weight } & \multirow[b]{2}{*}{$\mathrm{n}$} & \multicolumn{2}{|c|}{ Gain weight } & \multicolumn{3}{|c|}{ Not Change weight ${ }^{\prime}$} & \multirow[b]{2}{*}{ P-value 4} \\
\hline & $\mathrm{n}$ & $\mathrm{BM} \mathrm{I}^{2}$ & $95 \% \mathrm{Cl}^{3}$ & & $\mathrm{BMI}$ & $95 \% \mathrm{Cl}$ & $\mathrm{n}$ & $\mathrm{BMI}$ & $95 \% \mathrm{Cl}$ & \\
\hline \multicolumn{11}{|c|}{ Breakfast consumption (days per school week) } \\
\hline None & 347 & 28.8 & $(27.1,30.5)$ & 76 & 21.3 & $(19.9,22.8)$ & 266 & 25.0 & $(23.7,25.9)$ & \\
\hline I-2 days & 225 & 29.4 & $(28.1,30.7)$ & 48 & 22.7 & $(20.9,24.4)$ & 156 & 25.0 & $(23.4,25.9)$ & \\
\hline $3-4$ days & 425 & 28.8 & $(27.4,30.1)$ & 142 & 21.3 & $(20.2,22.4)$ & 357 & 24.4 & $(22.9,25.8)$ & \\
\hline 5 days & 465 & 28.1 & $(26.8,29.3)$ & 149 & 20.8 & $(19.7,21.8)$ & 423 & 22.5 & $(21.7,23.4)$ & 0.003 \\
\hline \multicolumn{11}{|c|}{ Eat five or more fruits and vegetables a day } \\
\hline No & 886 & 28.2 & $(27.0,29.4)$ & 294 & 21.1 & $(19.7,22.6)$ & 847 & 23.9 & $(22.8,25.0)$ & \\
\hline Yes & 773 & 29.0 & $(27.7,30.3)$ & 180 & 21.5 & $(21.0,22.0)$ & 505 & 23.6 & $(22.6,24.6)$ & 0.001 \\
\hline \multicolumn{11}{|c|}{ Average daily soft drink consumption } \\
\hline Not regular drinker & 394 & 28.0 & $(26.5,29.4)$ & 78 & 20.5 & $(19.1,22.0)$ & 285 & 22.9 & $(21.4,24.3)$ & \\
\hline$\leq \mathrm{I} / 2$ a can a day & 518 & 28.7 & $(27.4,29.9)$ & 125 & 20.6 & $(19.0,22.2)$ & 410 & 23.4 & $(22.1,24.6)$ & \\
\hline I can a day & 294 & 28.7 & $(27.3,30.0)$ & 94 & 21.5 & $(19.8,23.3)$ & 267 & 24.1 & $(23.1,25.1)$ & \\
\hline 2 cans a day & 148 & 29.3 & $(27.2,31.4)$ & 56 & 22.5 & $(21.2,23.9)$ & 136 & 24.8 & $(23.1,26.5)$ & \\
\hline$>2$ cans a day & 169 & 28.8 & $(27.3,30.3)$ & 71 & 21.6 & $(20.5,22.7)$ & 158 & 25.0 & $(24.1,25.8)$ & 0.038 \\
\hline \multicolumn{11}{|c|}{ Fast food/takeaway consumption } \\
\hline Once a month or less & 388 & 29.0 & $(27.4,30.5)$ & 75 & 20.6 & $(18.6,22.7)$ & 231 & 23.3 & $(21.9,24.6)$ & \\
\hline 2-3 times/month & 495 & 28.5 & $(27.5,29.4)$ & 115 & 21.3 & $(20.1,22.4)$ & 363 & 23.9 & $(22.5,25.3)$ & \\
\hline I-3 times/week & 674 & 28.5 & $(27.0,30.0)$ & 228 & 21.3 & $(20.2,22.5)$ & 660 & 23.8 & $(23.0,24.7)$ & \\
\hline Most days & 102 & 28.3 & $(26.2,30.3)$ & 56 & 22.0 & $(21.0,23.0)$ & 98 & 24.6 & $(22.8,26.3)$ & $<0.001$ \\
\hline \multicolumn{11}{|c|}{ High fat foods as after school snack } \\
\hline Never & 456 & 28.3 & $(26.9,29.7)$ & 84 & 20.2 & $(|8.6,2| .7)$ & 334 & 22.7 & $(21.5,23.9)$ & \\
\hline Some days & 850 & 28.8 & $(27.6,30.0)$ & 217 & 21.3 & $(20.1,22.4)$ & 668 & 24.0 & $(23.2,24.9)$ & \\
\hline Most days & 259 & 28.6 & $(27.2,29.9)$ & 117 & 22.1 & $(21.3,22.9)$ & 257 & 24.2 & $(22.9,25.5)$ & \\
\hline Everyday & 94 & 28.4 & $(26.8,30.0)$ & 56 & 21.2 & $(19.6,22.8)$ & 93 & 24.9 & $(23.6,26.2)$ & 0.001 \\
\hline \multicolumn{11}{|c|}{ High sugar foods as after school snack } \\
\hline Never & 375 & 29.2 & $(28.2,30.2)$ & 90 & 21.7 & $(19.6,23.7)$ & 279 & 23.8 & $(22.5,25.1)$ & \\
\hline Some days & 835 & 28.6 & $(27.2,30.0)$ & 214 & 21.2 & $(20.7,21.8)$ & 640 & 23.8 & $(22.9,24.6)$ & \\
\hline Most days & 306 & 28.1 & $(26.9,29.2)$ & 110 & 21.0 & $(19.3,22.7)$ & 288 & 23.6 & $(22.2,25.0)$ & \\
\hline Everyday & 143 & 27.9 & $(26.4,29.3)$ & 60 & 21.3 & $(20.1,22.5)$ & 145 & 24.3 & $(22.4,26.1)$ & $<0.001$ \\
\hline \multicolumn{11}{|c|}{ Fruit as after school snack } \\
\hline Never & 185 & 27.3 & $(25.6,28.9)$ & 91 & 21.0 & $(19.5,22.5)$ & 204 & 23.8 & $(23.0,24.7)$ & \\
\hline Some days & 709 & 28.9 & $(27.6,30.1)$ & 207 & 21.2 & $(20.1,22.4)$ & 592 & 23.9 & $(22.8,24.9)$ & \\
\hline Most days & 426 & 29.1 & $(27.8,30.4)$ & 98 & 22.0 & $(20.7,23.3)$ & 295 & 24.2 & $(22.6,25.8)$ & \\
\hline Everyday & 339 & 28.0 & $(26.7,29.4)$ & 78 & 20.9 & $(20.0,21.7)$ & 261 & 23.1 & $(21.7,24.4)$ & $<0.001$ \\
\hline
\end{tabular}

IIncludes students who were trying to stay the same weight or not trying to do anything about their weight.

2 Unadjusted mean

$395 \%$ Confidence Interval $(\mathrm{Cl})$ for the mean

${ }^{4} \mathrm{p}$-value for the interaction term expressed as behavior*weight control attempt, controlling for age, sex, and ethnicity

oeconomic position in the current study was school decile. It is possible that student household income could vary within the schools and that household income could have an independent confounding effect. However, indicators from the 2001 Census of the main intervention area for the OPIC study suggest that this area is relatively economically disadvantaged and there may not be much variation in household socioeconomic position[30] Also ethnicity is highly correlated with socioeconomic indicators in New Zealand [31] and we have controlled for the effects of ethnicity in the current analyses.

\section{Conclusion}

Findings from the current study suggest that attempts to change weight significantly modified the relationships between BMI and nutrition behaviors. This finding is important to consider in future cross-sectional studies of BMI and nutrition behaviors, especially among populations who may be heavily targeted by obesity prevention programs. Future cross-sectional research may need to exclude people who are currently trying to lose weight from analyses examining the relationships between nutrition behaviors and BMI. This approach has been previ- 
ously used to correct for confounding by smoking in the relationships between BMI and mortality[32]. Future studies examining relationships between BMI and nutrition behaviours that report nonsignificant or unexpected findings should consider that attempts to change weight may be modifying these relationships.

Our findings also suggest that the young people in our study are already adopting healthier behaviors in attempt to control their weight. To improve the effectiveness of obesity prevention programs, efforts may be better targeted to younger children and their families to adopt healthier eating practices before they become overweight since weight loss is difficult to achieve. Adolescents who diet to lose weight are more likely to gain weight into adulthood[33] and are more likely to adopt more extreme dieting behaviors [34]. Environmental changes that support young people in eating healthy foods may improve the effectiveness of existing obesity prevention programs that are primarily education-based by supporting young people to change and maintain their dietary patterns[35].

\section{Competing interests}

The author(s) declare that they have no competing interests.

\section{Acknowledgements}

The Pacific OPIC study was funded by the Wellcome Trust, the New Zealand Health Research Council and the National Health and Medical Research Council of Australia. The investigators for the OPIC study are Boyd Swinburn (Deakin University), Robert Scragg (University of Auckland), and Jan Pryor (Fiji School of Medicine).

\section{References}

I. Parnell W, Scragg R, Wilson N, Schaaf D, Fitzgerald E: NZ Food NZ Children: Key results of the 2002 National Children's Nutrition Survey. Wellington, New Zealand, Ministry of Health; 2003.

2. Wang $Y$, Lobstein $T$ : Worldwide trends in childhood overweight and obesity. International Journal of Pediatric Obesity 2006, I: I I-25.

3. Adolescent Health Research Group: A health profile of New Zealand youth who attend secondary school. N Z Med J 2003, I | 6(I I I I ):U380.

4. Boutelle K, Neumark-Sztainer D, Story M, Resnick M: Weight control behaviors among obese, overweight, and nonoverweight adolescents. J Pediatr Psychol 2002, 27(6):53 I-540.

5. Neumark-Sztainer D, Story M, Falkner NH, Beuhring T, Resnick MD: Sociodemographic and personal characteristics of adolescents engaged in weight loss and weight/muscle gain behaviors: who is doing what? Prev Med 1999, 28(I):40-50.

6. Dietz WH Jr., Gortmaker SL: Do we fatten our children at the television set? Obesity and television viewing in children and adolescents. Pediatrics 1985, 75(5):807-8I2.

7. Gortmaker SL, Peterson K, Wiecha J, Sobol AM, Dixit S, Fox MK, Laird N: Reducing obesity via a school-based interdisciplinary intervention among youth: Planet Health. Arch Pediatr Adolesc Med 1999, 153(4):409-418.

8. Robinson TN: Reducing children's television viewing to prevent obesity: a randomized controlled trial. JAMA 1999, 282(16): I56I-I567.

9. Fiore $\mathrm{H}$, Travis $\mathrm{S}$, Whalen A, Auinger P, Ryan S: Potentially protective factors associated with healthful body mass index in adolescents with obese and nonobese parents: a secondary data analysis of the third national health and nutrition examination survey, 1988-1994. J Am Diet Assoc 2006, 106(1):55-64.

10. Cole TJ, Bellizzi MC, Flegal KM, Dietz WH: Establishing a standard definition for child overweight and obesity worlwide: international survey. $B M J 2000,320: 1240-1243$.

II. French SA, Story M, Neumark-Sztainer D, Fulkerson JA, Hannan P: Fast food restaurant use among adolescents: associations with nutrient intake, food choices and behavioral and psychosocial variables. International Journal of Obesity \& Related Metabolic Disorders: Journal of the International Association for the Study of Obesity 200I, 25(12): 1823-1833.

12. Ludwig DS, Peterson KE, Gortmaker SL: Relation between consumption of sugar-sweetened drinks and childhood obesity: a prospective, observational analysis. Lancet 200I, 357(9255):505-508.

13. Rampersaud GC, Pereira MA, Girard BL, Adams J, Metzl JD: Breakfast habits, nutritional status, body weight, and academic performance in children and adolescents. J Am Diet Assoc 2005, 105(5):743-60; quiz 76I-2.

14. Thompson OM, Ballew C, Resnicow K, Must A, Bandini LG, Cyr H, Dietz WH: Food purchased away from home as a predictor of change in BMI z-score among girls. International Journal of Obesity \& Related Metabolic Disorders: Journal of the International Association for the Study of Obesity 2004, 28(2):282-289.

15. Utter J, Scragg R, Schaaf D, Fitzgerald E, Wilson N: Correlates of body mass index among a nationally representative population of New Zealand children. International Journal of Pediatric Obesity 2007, 2: 104-1 I3.

16. Ogden CL, Carroll MD, Curtin LR, McDowell MA, Tabak CJ, Flegal KM: Prevalence of overweight and obesity in the United States, 1999-2004. JAMA 2006, 295(13):1549-1555.

17. Saxena S, Ambler G, Cole TJ, Majeed A: Ethnic group differences in overweight and obese children and young people in England: cross sectional survey. Arch Dis Child 2004, 89(I):30-36.

18. Booth ML, Wake M, Armstrong T, Chey T, Hesketh K, Mathur S: The epidemiology of overweight and obesity among Australian children and adolescents, 1995-97. Aust N Z J Public Health 200I, 25(2): 162-169.

19. Schulze MB, Manson JE, Ludwig DS, Colditz GA, Stampfer MJ, Willett WC, Hu FB: Sugar-sweetened beverages, weight gain, and incidence of type 2 diabetes in young and middle-aged women. JAMA 2004, 292(8):927-934.

20. Nicklas TA, Yang SJ, Baranowski T, Zakeri I, Berenson G: Eating patterns and obesity in children. The Bogalusa Heart Study. Am J Prev Med 2003, 25(I):9-16.

21. Berkey CS, Rockett HR, Field AE, Gillman MW, Colditz GA: Sugaradded beverages and adolescent weight change. Obes Res 2004, I 2(5):778-788.

22. Guthrie JF, Lin BH, Frazao E: Role of food prepared away from home in the American diet, $1977-78$ versus 1994-96: changes and consequences. Journal of Nutrition Education \& Behavior 2002, 34(3): $140-150$.

23. Briefel RR, Sempos CT, McDowell MA, Chien S, Alaimo K: Dietary methods research in the third National Health and Nutrition Examination Survey: underreporting of energy intake. $\mathrm{Am} J$ Clin Nutr 1997, 65(4 Suppl): I 203S-1209S.

24. Rennie KL, Jebb SA, Wright A, Coward WA: Secular trends in under-reporting in young people. Br J Nutr 2005, 93(2):24I-247.

25. Bandini LG, Must A, Cyr H, Anderson SE, Spadano JL, Dietz WH: Longitudinal changes in the accuracy of reported energy intake in girls 10-15 y of age. Am J Clin Nutr 2003, 78(3):480-484.

26. Bandini LG, Schoeller DA, Cyr HN, Dietz WH: Validity of reported energy intake in obese and nonobese adolescents. Am J Clin Nutr 1990, 52(3):42 I-425.

27. Stice $E$, Fisher M, Lowe MR: Are dietary restraint scales valid measures of acute dietary restriction? Unobtrusive observational data suggest not. Psychological Assessment 2004, I 6(I):5I-59.

28. Lowry R, Galuska DA, Fulton JE, Wechsler H, Kann L: Weight management goals and practices among U.S. high school students: associations with physical activity, diet, and smoking. J Adolesc Health 2002, 31 (2): $133-144$.

29. Pesa JA, Turner LW: Fruit and vegetable intake and weightcontrol behaviors among US youth. American Journal of Health Behavior 200I, 25(I):3-9. 
30. Citizen and Customer Services: Mangere Ward, Census 200 I Results. [http://www.manukau.govt.nz/default.aspx?page=statis tics].

31. Howden-Chapman P, Tobias M: Social Inequalities in Health: New Zealand 1999. Wellington, Ministry of Health; 2000.

32. Manson JE, Willett WC, Stampfer MJ, Colditz GA, Hunter DJ, Hankinson SE, Hennekens CH, Speizer FE: Body weight and mortality among women. N Engl J Med I995, 333(I I):677-685.

33. Viner RM, Cole TJ: Who changes body mass between adolescence and adulthood? Factors predicting change in BMI between 16 year and 30 years in the 1970 British Birth Cohort. Int J Obes 2006, 30: 1368-1374.

34. Neumark-Sztainer D, Wall M, Guo J, Story M, Haines J, Eisenberg M: Obesity, disordered eating, and eating disorders in a longitudinal study of adolescents: how do dieters fare 5 years later? J Am Diet Assoc 2006, 106(4):559-568.

35. French SA, Story M, Jeffery RW: Environmental influences on eating and physical activity. Annu Rev Public Health 200I, 22:309-335.

Publish with Bio Med Central and every scientist can read your work free of charge

"BioMed Central will be the most significant development for disseminating the results of biomedical research in our lifetime. "

Sir Paul Nurse, Cancer Research UK

Your research papers will be:

- available free of charge to the entire biomedical community

- peer reviewed and published immediately upon acceptance

- cited in PubMed and archived on PubMed Central

- yours - you keep the copyright

Submit your manuscript here:

http://www.biomedcentral.com/info/publishing_adv.asp
BioMedcentral 